\title{
Retrospective analysis of elective hysterectomy cases in a tertiary care centre
}

\author{
Divya R. Prasad*, Neelima V. Nair
}

Department of Obstetrics and Gynecology, Sree Gokulam Medical College and Research Foundation, Venjaramoodu, Trivandrum, Kerala, India

Received: 01 July 2018

Accepted: 27 July 2018

*Correspondence:

Dr. Divya R. Prasad,

E-mail:ms.divanil@rediffmail.com

Copyright: (c) the author(s), publisher and licensee Medip Academy. This is an open-access article distributed under the terms of the Creative Commons Attribution Non-Commercial License, which permits unrestricted non-commercial use, distribution, and reproduction in any medium, provided the original work is properly cited.

\begin{abstract}
Background: Often hysterectomy remains the only option available in many gynaecological conditions, though it is resented by most women. This study aims to analyse the cases of hysterectomy performed in a tertiary care centre in India, with a view to modify and improve health care provided to women.

Methods: A retrospective analysis of 500 cases of elective hysterectomy in Sree Gokulam Medical College and Research Foundation from January 2016 to December 2017 was done from hospital records. The observations according to age, indications of hysterectomy, route of hysterectomy and preservation of ovaries were statistically analysed.

Results: $35.2 \%$ (176 cases) were between 45 and 50 years. Mean age was $48 \pm 2$ years. $90.4 \%$ (452 cases) were done in women above 40 years of age. The commonest indication for hysterectomy was symptomatic fibroid uterus $59.4 \%$ (297 cases). 81.8\% (409 cases) women underwent abdominal hysterectomy while $18.2 \%$ (91 cases) women underwent vaginal hysterectomy or laparoscopic assisted vaginal hysterectomy. 84.6\% (77 of 91 cases) of vaginal hysterectomy was done for prolapse uterus. Preservation of one or both ovaries was done in 47.2\% (236 cases).

Conclusions: Hysterectomy is usually done after the age of 40 years with the mean age being $48 \pm 2$ years. Symptomatic fibroid uterus was the most common indication. The rates of vaginal hysterectomy were lower for indications other than prolapse uterus. Ovaries were preserved in several cases.
\end{abstract}

Keywords: Hysterectomy, Indication, Preservation of ovaries, Route

\section{INTRODUCTION}

Hysterectomy is the second most common surgery done in women, next only to caesarean section. According to International database 2014, in India 2.16/1000 women have had hysterectomy. ${ }^{1}$ A study by Desai et al, from Gujarat has shown that $13 \%$ of women had undergone hysterectomy at an average age of 37 years, in India.

The common indications of hysterectomy are fibroid uterus, abnormal uterine bleeding, ovarian tumour, utero vaginal prolapse, malignancies of uterus, cervix and ovaries. The indications of hysterectomy vary from benign to malignant conditions.

Hysterectomy is done through various routes viz., abdominal, vaginal and laparoscopic. This usually depends on the surgeon's preference and patient's choice.

Hysterectomy is sometimes done with removal of one or both adnexa especially in women above 45 years. When concurrent oophorectomy is done in premenopausal women, early menopause with its complications like psycho sexual dysfunction, osteoporosis and cardiovascular complications can occur. 
This study aims to analyse the hysterectomy cases performed in a tertiary care centre over a period of one year and attempts to analyse the cases based on age, common indications, route of hysterectomy and preservation of ovaries, in order to improve health care.

\section{METHODS}

This is a retrospective study conducted from January 2016 to December 2017 in the department of obstetrics and gynaecology, Sree Gokulam medical college, Venjaramoodu, Trivandrum. Sample size for the present study was 500 cases.

\section{Inclusion criteria}

The study included all patients who underwent elective hysterectomy in Sree Gokulam Medical College during the one-year period of study.

\section{Exclusion criteria}

The study did not include emergency hysterectomy and caesarean hysterectomy.

Patients were identified from hospital records. Data regarding age, indications, route of hysterectomy and preservation of ovaries, was collected from the hospital records. Abdominal hysterectomy included total abdominal hysterectomy (TAH), total abdominal hysterectomy with unilateral salpingo-oophorectomy (TAH USO), and total abdominal hysterectomy with bilateral salpingo-oophorectomy (TAH BSO). It also included hysterectomy done as a part of staging laparotomy for malignancies. Vaginal hysterectomy included vaginal hysterectomy with pelvic floor repair (VH PFR), done for uterovaginal prolapse, non-descent vaginal hysterectomy (NDVH) done for indications other than prolapse and laparoscopic vaginal hysterectomy (LAVH).

\section{Statistical analysis}

Data collected was analysed statistically using SPSS 20 IBM statistics. Descriptive statistics based on the parameters of age, indications, route and preservation of ovaries were taken and presented in percentages. Comparison of variables were done using chi squared test and significance was set at $\mathrm{P}<0.05$.

\section{RESULTS}

\section{Age}

Majority of patients, i.e., 35.2\% (176) were between 45 and 50 years of age. Hysterectomy was done at less than 40 years in $9.6 \%$ (48) (Table 1). Mean age was $48 \pm 2$ years.
Table 1: Age distribution.

\begin{tabular}{|c|c|c|}
\hline Age in years & Frequency & Percentage \\
\hline$<40$ & 48 & 9.6 \\
\hline $40-44$ & 146 & 29.2 \\
\hline $45-50$ & 176 & 35.2 \\
\hline$>50$ & 130 & 26 \\
\hline total & 500 & 100 \\
\hline
\end{tabular}

\section{Indication}

Most common indication for elective hysterectomy was symptomatic fibroids. This constituted 59.4\% (297 cases). $15.4 \%$ (77 cases) were done for benign ovarian tumour. Premalignant lesions of the cervix and malignancies of ovary and endometrium contributed to $1.6 \%$ (8cases) (Table 2).

Table 2: Indications of hysterectomy.

\begin{tabular}{|lll|}
\hline Indications & Frequency & Percentage \\
\hline Fibroid uterus & 297 & 59.4 \\
\hline Uterovaginal prolapse & 77 & 15.4 \\
\hline Benign ovarian tumour & 37 & 7.4 \\
\hline AUB & 26 & 5.2 \\
\hline Postmenopausal bleeding & 20 & 4 \\
\hline Adenomyosis & 18 & 3.6 \\
\hline Endometriosis & 12 & 2.4 \\
\hline Malignant ovarian tumour & 5 & 1 \\
\hline $\begin{array}{l}\text { Cervical intraepithelial } \\
\text { neoplasia }\end{array}$ & 2 & 0.4 \\
\hline Carcinoma endometrium & 1 & 0.2 \\
\hline Vaginal elongation cervix & 3 & 0.6 \\
\hline $\begin{array}{l}\text { Pelvic inflammatory } \\
\text { disease }\end{array}$ & 2 & 0.4 \\
\hline total & 500 & 100 \\
\hline
\end{tabular}

Table 3: Routes of hysterectomy.

\begin{tabular}{|llll|}
\hline Route & Types & Frequency & Percentage \\
\hline $\begin{array}{l}\text { Abdominal } \\
81.8 \%\end{array}$ & TAH & 127 & 25.4 \\
\cline { 2 - 4 }$(409)$ & TAH USO & 18 & 3.6 \\
\cline { 2 - 4 } VAH BSO & 264 & 52.8 \\
Vaginal & VH PFR & 77 & 15.4 \\
\cline { 2 - 4 } 18.2\% (91) & NDVH & 10 & 2.0 \\
\cline { 2 - 4 } Total & LAVH & 4 & 0.8 \\
\hline
\end{tabular}

(TAH total abdominal hysterectomy, TAH USO- total abdominal hysterectomy with unilateral salpingo oophorectomy, TAH BSO - total abdominal hysterectomy with bilateral salpingo oophorectomy, VH PFR - vaginal hysterectomy with pelvic floor repair, NDVH - Non descent vaginal hysterectomy, LAVH- laparoscopic assisted vaginal hysterectomy)

\section{Route of hysterectomy}

In $81.8 \%$ (409 cases), hysterectomy was done through the abdominal route. Hysterectomy was done through the vaginal route in $18.2 \%$ (91cases) of which $17.4 \%$ 
(87cases) were vaginal hysterectomies and $0.8 \%$ (4 cases) were laparoscopic assisted vaginal hysterectomies (Table $3)$.

\section{Preservation of ovaries}

One or both ovaries were preserved in $47.2 \%$ (236 cases) (Table 4).

Table 4: Preservation of ovaries.

\begin{tabular}{|lll|}
\hline Preservation of ovaries & Frequency & Percentage \\
\hline $\begin{array}{l}\text { One or both ovaries } \\
\text { preserved }\end{array}$ & 236 & 47.2 \\
\hline Both ovaries removed & 264 & 52.8 \\
\hline Total & 500 & 100 \\
\hline
\end{tabular}

\section{DISCUSSION}

Hysterectomy is one of the commonest major surgical procedure done in women, probably next only to caesarean section.

About $75 \%$ of hysterectomy is done between 20 and 49 years of age 3 . Pandey et al4 in their study pointed that the mean age of women undergoing hysterectomy was $48 \pm 9.9$ years. In our study, $35.2 \%$ of patients were between $45-50$ years and the mean age was $48 \pm 2$ years.

In present study, the commonest indication for elective hysterectomy was symptomatic fibroid uterus in 59.4\%. Study done by Pandey et al showed a 39.9\% incidence of fibroid uterus in hysterectomy patients. ${ }^{4}$ Bala et al showed an incidence of $34 \%$ of fibroids in hysterectomy patients. ${ }^{1}$ Present study showed a slightly higher incidence of fibroid uterus. However, the rates of prolapse (15.4\%) and AUB (5.2\%) were similar to other studies. Wu et al, Hysterectomy rates in US 2003 showed a similar rate of $37 \%$ leiomyoma as indication for hysterectomy. ${ }^{5}$

Patient acceptance of non-surgical methods of management viz., medical management, endometrial ablation, uterine artery embolization (UAE) and levonorgestrel intra uterine system (LNG IUS) is less. Oral medication suits a minority of women long term. ${ }^{6}$ Hysterectomy offers a permanent relief. Hysterectomy reduces menstrual bleeding more than medical treatment at 1 year. LNG IUS is equally effective in improving quality of life. UAE though has a patient satisfaction rate similar to hysterectomy and myomectomy, has an increased likelihood of requirement of surgical intervention within 2.5 years of initial procedure. ${ }^{7}$ Emergence of effective medical and conservative treatment for benign conditions is questioning the need for hysterectomy. The uterus should not be considered as a vestigial organ after child bearing. Studies have proved that following hysterectomy women suffer from psycho sexual dysfunction8 and increased incidence of vault prolapse.
In present study, $81.8 \%$ hysterectomy was done through abdominal route and $18.2 \%$ through vaginal route. This included vaginal hysterectomy and laparoscopic assisted vaginal hysterectomy. Bala et al study also showed a $91.4 \%$ rate of abdominal hysterectomy and $8.6 \%$ rate of vaginal hysterectomy. ${ }^{1} \mathrm{Wu}$ et al5 from US showed abdominal hysterectomy rates of $66.1 \%$, vaginal hysterectomy $21.8 \%$ and LAVH $11.8 \% .{ }^{5}$ In present study, only negligible $0.4 \%$ of cases were done by laparoscopic route. It is unclear what proportion of hysterectomy should be performed by each route. The route of surgery must be individualized to the patient and surgeon preference. Numerous determining factors include indications for surgery, patient characteristics including body mass index, prior surgeries, concomitant procedures, risk of complications, length of hospital stay, recovery and cost effectiveness. Overall, vaginal hysterectomy is considered the surgery of choice if it is feasible, because the vaginal route is associated with fewer complications than other methods. ${ }^{9-12}$. When vaginal and laparoscopic routes are compared, studies have shown that laparoscopy does not provide any added benefit but is associated with higher cost. ${ }^{11,13}$

Both ovaries were removed in $52.8 \%$ of present cases. In a study by Bala et al, both ovaries were removed in $87.3 \%$ cases while a study done by Manesh MD et al, both ovaries were removed in only $43 \%$ cases which is similar to present study. ${ }^{1,4}$ The merit of doing concurrent oophorectomy during hysterectomy continues to be debated for women not at high risk for developing ovarian cancer.

Estimates regarding the number of prophylactic oophorectomies needed to prevent one case of ovarian cancer range from 200 to 300 . Benefits such as prevention of ovarian cancer need to be weighed against an instant surgical menopause that may increase the woman's risk of ischemic heart disease and osteoporosis. Ovarian endocrine function is thought to wean off more rapidly after removal of their target organ. Mean age of onset of menopause in those who underwent hysterectomy is 3.7 years earlier than average even when ovaries are preserved.

\section{CONCLUSION}

Hysterectomy is done after the age of 40 years with the mean age being $48 \pm 2$ years. Symptomatic fibroid uterus was the commonest indication. The rates of vaginal hysterectomies were lower for indications other than uterovaginal prolapse. Ovaries were preserved in a number of cases. Patient should be encouraged to seek conservative management for gynaecologic conditions whenever possible. Gynaecologists should try to do more hysterectomies through vaginal route as it is associated with better patient comfort and less morbidity. Ovaries should be preserved in women at low risk for malignancies. 


\section{ACKNOWLEDGEMENT}

Authors would like to thank Dr. P. B. Sulekha Devi, Dr. Bhavani L. Nair for his support during study

Funding: No funding sources Conflict of interest: None declared

Ethical approval: Not required

\section{REFERENCES}

1. Bala R, Devi Pratima K, Singh CM. Trend of hysterectomy. A retrospective analysis in RIMS, Imphal. Int J Gynaecol Obstet India. 2013;29(1): 4-7.

2. Desai S, Sinha T, Mahal A. Prevalence of hysterectomy among rural and urban women with and without health insurance in Gujarat, India. Reprod Health Matters. 2011 Jan 1;19(37):42-51.

3. Rajeshwari BV, Hishikar V. Views and reviews of hysterectomy: a retrospective study of 260 cases over a period of 1 year. Bombay Hospital J. 2008;50(1):59.

4. Pandey D, Sehgal K, Saxena A, Hebbar S, Nambiar J, Bhat RG. An audit of indications, complications, and justification of hysterectomies at a teaching hospital in India. Int J Reprod Med. 2014;2014.

5. Wu JM, Wechter ME, Geller EJ, Nguyen TV, Visco AG. Hysterectomy rates in the United States, 2003. Obstet Gynecol. 2007 Nov 1;110(5):1091-5.

6. Lethaby A, Shepperd S, Cooke I, Farquhar C. Endometrial resection and ablation versus hysterectomy for heavy menstrual bleeding. The Cochrane Database System Rev. 2000(2):CD000329.

7. Gupta JK, Sinha AS, Lumsden MA, Hickey M. Uterine artery embolization for symptomatic uterine fibroids. Cochrane Database Syst Rev. 2006;5(1):ID CD 005073, 2006.

8. McPherson K, Herbert A, Judge A, Clarke A, Bridgman S, Maresh $\mathrm{M}$ et al. Psychosexual health 5 years after hysterectomy: population-based comparison with endometrial ablation for dysfunctional uterine bleeding. Health Expectations. 2005 Sep;8(3):234-43.

9. Johnson N, Barlow D, Lethaby A, Tavender E, Curr E, Garry R. Surgical approach to hysterectomy for benign gynaecological disease (Cochrane Review). In: Cochrane Library, Oxford: Update Software. 2006(2).

10. Meikle SF, Nugent EW, Orleans M. Complications and recovery from laparoscopy-assisted vaginal hysterectomy compared with abdominal and vaginal hysterectomy. Int J Gynecol Obstet. 1997 Feb $1 ; 57(2): 242$.

11. Summitt JR, Stovall TG, Lipscomb GH, Ling FW. Randomized comparison of laparoscopy-assisted vaginal hysterectomy with standard vaginal hysterectomy in an outpatient setting. Obstet Gynecol. 1992 Dec;80(6):895-901.

12. ACOG Committee Opinion. Number 311, April 2005. Appropriate use of laparoscopically assisted vaginal hysterectomy. Obstet Gynecol. 2005 Apr;105(4):929-30.

13. Garry R, Fountain J, Brown J, Manca A, Mason S, Sculpher $M$ et al. evaluate hysterectomy trial: a multicentre randomised trial comparing abdominal, vaginal and laparoscopic methods of hysterectomy. Health technology assessment (Winchester, England). 2004 Jun;8(26):1-54.

14. Maresh MJ, Metcalfe MA, McPherson K, Overton C, Hall V, Hargreaves $\mathrm{J}$ et al. The value national hysterectomy study: description of the patients and their surgery. BJOG: Int J Obstet Gynaecol. 2002 Mar;109(3):302-12.

Cite this article as: Prasad DR, Nair NV. Retrospective analysis of elective hysterectomy cases in a tertiary care centre. Int J Reprod Contracept Obstet Gynecol 2018;7:3714-7. 